\title{
VOORBEREIDING VIR AFTREDE EN BEJAARDHEID
}

\section{MEJ. A. GERRETSEN}

\section{SUMMARY}

The number of retired persons in the community is increasing steadily. Retirement is a relatively modern concept and the problems associated with it are not yet fully understood.

People should prepare themselves for retirement to ensure that it will be a creative and satisfying time of life. There are currently a number of programmes to prepare workers for retirement such as the one offered by the Retirement Association.

The nurse has a role in motivating members of the community to plan for retirement and should include this topic in health education, using a non-directive approach. She can also help to create a more positive attitude towards retirement and retired people among the younger members of the community.

\section{WAT IS AFTREDE?}

Aktiwiteit is ' $n$ essensiële deel van 'n mens se lewe en vir die meeste mense is die belangrikste en belonendste aktiwiteit sy beroep. Hierdie aktiwiteit is so belangrik dat dit een derde van 'n mens se dag in beslag neem. Dan skielik kom daar 'n einde aan. Dit word afgegrens deur die tradisionele baken van 'n partytjie, 'n toekenning en/of 'n pensioen. Aan die een kant van die baken was arbeid - aan die ander kant, geen arbeid meer nie. Aftree beteken om uit die diens te tree, betrekking of amp neer te lê, maar word die indiwidu se gewilligheid tot hierdie stap oorweeg?

Die konsep van aftree en pensioen is relatief gesproke 'n begrip van die twintigste eeu. Dit is 'n moderne idee dat elke werkende man of vrou hul betrekking op 'n sekere ouderdom moet staak en daarna ' $n$ bestaan met ' $n$ versekerde inkomste moet voer. In werklikheid is dit so nuut dat daar nog nie geleentheid was om die werklike implikasies daarvan in oënskou te neem nie. Daar is dus nog nie genoegsame aandag geskenk aan die gedagte van voorbereiding vir aftrede nie $(6: p 9)$. Ouers beplan 'n kind se skoolloopbaan, die adolessent beplan sy werksloopbaan, die jong persoon beplan sy huwelik, daar word beplan vir bevordering in die beroep van jou keuse en baie beplan vir die dood deur die opstel van 'n testament of uitneem van 'n begrafnisversekering. Hoekom word daar dan nie daadwerklik vir aftrede beplan nie? (9:p8)

Weens verskillende faktore, soos die vooruitgang in mediese tegnologie, is daar 'n aanwas in die hoeveelheid aftredes in die gemeenskap. In die Westerse wêreld alleenlik is daar 291 miljoen persone bo die ouderdom van 60 jaar en elke dag is daar veertien duisend mense wat aftree, ongeag hul potensiële bydrae tot die industrie, handel en staat (7:p55). Die behoeftes van hierdie groep in die gemeenskap word al hoe groter en belangriker aangesien die werkkrag van die gemeenskap nie die aftreder vir 'n onbepaalde tydperk kan onderhou nie. Tegnologiese vooruitgang moedig vroeë aftrede aan. Rekenaars vervang 'n groot aantal werknemers en in sekere lande word werknemers 'n bedrag geld betaal indien hulle op 60 jaar in stede van 65 jaar aftree. Hierdie persone het dan moontlik nog twintig aktiewe lewensjare oor waarvoor hulle onvoorbereid is.

In 1900 was $6 \%$ van Brittanje se bevolking op aftree-ouderdom en die meeste sonder pensioen. In 1975 het die aantal tot $20 \%$ gestyg. Hierdie persone se lewenstandaard moet styg met dié van die res van die bevolking, en die finansiële implikasies hiervan is verreikend. 'n Voldoende inkomste na aftrede sal afhang van die persoon se pensioen en eie spaargeld. Indien persone dus op vroeër ouderdom begin aftree en geneeskunde die persoon se aktiewe lewe verleng, is voorligting vir aftrede noodsaaklik - nie net oor wat die persoon met sy pensioengeld gaan doen nie, maar ook wat hy met homself gaan doen (6:p11).

Dit is ooglopend dat die verskynsel van bejaardheid nie voorkom kan word nie - so ook nie die problematiek en ontwrigting wat dit meebring nie. Daarenteen kan ons wel stappe doen om in ' $n$ sekere mate die bejaarde se ekonomiese toestand te verlig deur hom by te staan met die probleme wat hy ondervind weens verpligte aftrede. Aftrede bring probleme mee vir die werkgewer sowel as die werknemer, alhoewel die probleemareas verskil. As die probleme opgelos gaan word, moet voorbereiding vir aftrede vroeg begin. Dit moet berus op 'n basiese kennis van die indiwidu, sy behoeftes, sy sienswyses, sy begeertes en sy moontlikhede om die doelwitte wat hy vir homself gestel het, te bereik. Goeie beplanning sal hierdie spesifieke behoeftes in ag neem en sodoende die suksesvolle praktiese toepassing daarvan verseker $(2: p 44)$.

Om die doelwit van veroudering met waardigheid en aansien te bereik moet daar aan die aspek van onderrig aan die jongere geslag aandag geskenk word. Dit moet by die jong persoon tuisgebring word dat bejaardheid nie noodwendig agteruitgang en nutteloosheid impliseer nie, maar dat dit in toene- 
mende gevalle 'n geleentheid vir die ouere persoon bied om nog verdere bydraes tot die gemeenskap te maak.

President Johnson van Amerika het in 1964 gesê: Since not everyone is blessed with the gift of long life, those who are so endowed should occupy a place of special honor among us (2:p187). Nogtans is die klem in ons gemeenskap op die jeug en die aktiwiteite en deelname van die jeug. Die jong persoon bejeën nie die bejaarde met die eerbied wat hom toekom nie. Hulle moet heropgevoed word sodat hierdie pessimisme ten opsigte van bejaardheid uit die weg geruim kan word. Die huidige houding moet vervang word deur een van aanvaarding, respek en gewilligheid om die ouer persoon se vermoëns raak te sien en dit tot voordeel van die bejaarde en die gemeenskap te gebruik.

Verskeie instansies het die behoeftes van die bejaarde identifiseer en die gemeenskap tot aksie genoop. Wat nou 'n dringende behoefte is, is dat alle pogings, afgesien van die professionele veld of belangstellingsgebied, saamgevoeg moet word om die leefwyse van die individu te bevorder sodat hy maksimale tevredenheid uit sy latere jare kan put (2:p188).

Verder kan aftrede gesien word as 'n proses van wedergeboorte. Soos alle geboorteprosesse is daar gevare aan verbonde; geringe probleme kan ontstaan en soms kan tragedies voorkom. Vir die meeste kan en behoort dit egter 'n vreugdevolle gebeurtenis te wees.

Soos in alle menslike situasies is voorkennis van die omvang van die gebeure 'n wyse waarop 'n treurspel vermy, probleme bekamp en sukses verseker kan word. Die verantwoordelikheid om te bepaal of sy aftrede 'n heuglike gebeure of 'n tragedie gaan wees berus by elke individu self.

Vroeër jare het 'n persoon tot en met sy dood ses dae van die week gewerk. Verandering het ingetree sodat daar in die meeste lande 'n 5 dagwerksweek is en 'n persoon op 65 jarige ouderdom moet aftree, afgesien van sy persoonlike gevoelens in die saak. Die geslag wat nou aftree, het nie die voorreg van ouerlike advies oor aftrede gehad nie, omdat aftrede skaars in hulle leeftyd bestaan het. Die mense in die gemeenskap weet hoe om hulle tande te borsel en 'n voedsame dieet te volg, maar geen kennis oor aftrede word aan hulle oorgedra op skool- of kollegevlak nie. Die meeste literatuur oor die onderwerp het eers die afgelope dekade verskyn (3:p7).

Retirement is not merely a alternation in your economics and activities. It is a deeply emotional introduction to a way of living you have never before experienced (3:p10). Alkoholiste Anoniem het al groot sukses behaal met die hantering van alkoholiste, en dit word daaraan toegeskryf dat die hulp deur reeds gerehabiliteerde alkoholiste aangebied word. Slegs 'n persoon wat deur die proses van aftrede gegaan het, kan werklik sê wat dit behels. Hy is akuut daarvan bewus dat daar faktore by aftrede betrokke is wat baie meer behels as slegs die aankweek van 'n stokperdjie en 'n strandhuis in Margate. Net hy het ervaar en beleef wat dit is om kollegas te verlaat, sy beroepstatus prys te gee en nie meer 'n redelike maandelikse salaris te ontvang nie. Terselfdertyd het hy die unieke vreugde en rustigheid ervaar om sy lewe op uitdagende wyse te lei (3:p11).

\section{VOORBEREIDING VIR AF- TREDE}

Hoeveel mense beplan werklik wat hulle na aftrede gaan doen? Baie gee soveel aandag daaraan as aan die gedagte om vir 'n naweek Mars toe te gaan, hoewel daar wel uitsonderings is. Dit is egter uiters noodsaaklik om vroeg daaraan te begin dink. Nou wonder 'n mens: wat is vroeg? Sommige voel dat 'n mens jou moet begin voorberei vir aftrede wanneer jy jou vir 'n loopbaan voorberei. Dit klink miskien belaglik, maar wat 'n persoon in sy vroeë leeftyd doen, beïnvloed die sukses van sy aftrede, omdat die intellektuele en emosionele voorbereiding dan al begin. Aktiwiteite waaraan ' $n$ persoon in sy twintiger jare deelgeneem het en wat nie met sy beroep te make gehad het nie, is die aktiwiteite wat uiteindelik tot 'n suksesvolle aftrede sal bydra. Derhalwe moet jong mense opgevoed word om 'n suksesvolle lewe te lei eerder as om slegs 'n suksesvolle beroep te beoefen. Die gedagte is dus opvoeding in 'n breë sin en nie slegs vir spesialisasie nie. Hoe dieper die groef en hoe enger die spesialisasie, des te moeiliker is dit om met aftrede by veranderde omstandighede aan te pas. Indien opvoeding dus primêr op 'n bestaan toegespits word sal dit nie vir die persoon by aftrede van veel waarde wees nie. 'n Breë opvoeding sal wye belangstelling en genot van die lewe in die geheel kweek (3:p18).

Dit is moeilik om iets te waardeer of te geniet as 'n mens nie in 'n sekere mate daarmee bekend is nie. Niemand kan byvoorbeeld klassieke musiek, kunswerke of skaak waardeer tensy hy 'n sekere mate van kennis daaroor het nie. Dit help dus nie om te dink dat jy in iets sal belangstel sonder dat jy daarmee bekend is nie. Eers nadat 'n mens jou lewensmaat ken, begin jy in hom/haar belangstel. As iemand dus werklik kennis van verskillende onderwerpe dra, sal hy 'n wye belangstelling kan aankweek. Hierdie belangstellings kan na aftrede beoefen word. As jou belangstelling daarenteen jou beroep, rolbal en gholf behels het, sal ' $n$ dieet van rolbal en gholf na aftrede jou spysvertering nadelig beïnvloed. 'n Mate van fisiese, emosionele en intellektuele voeding is essensieël. Vir gebalanseerde fisiese, psigiese, sosiale, emosionele en intellektuele welsyn na aftrede, moet verskeie belangstellings getoets en ondersoek word. Dan eers kan 'n bevredigende en uitdagende belangstelling suksesvol gekweek word. Dit is 'n tydrowende proses van probeer en weer probeer en kan beslis nie oornag verwerklik word nie (3:p26).

Die aankweek van 'n stokperdjie of tydverdryf alleen is nie voldoende nie. Die mens moet ook sy idee of filosofie oor die lewe en aftrede in perspektief kry. Dit is effens laat om 'n lewensfilosofie op 50 jaar te begin aankweek want dit is 'n stadige proses wat begin tydens adolessensie en eers verrykend is teen 40-50 jaar (7:p56). Volgens die Engelse Oxford-woordeboek beteken retire - to withdraw, go away, retreat, seek seclusion. Hierdie negatiewe beskrywing is dalk 'n weergawe van hoe baie mense oor 
aftrede voel. Die houding van die indiwidu sowel as die gemeenskap moet dus in oënskou geneem word, en die negatiewe konnotasie van die woord moet verwyder word (3:p46).

Weer eens moet beklemtoon word dat min mense in hulle vroeë leeftyd aan aftrede dink. Hulle besin nie oor die probleme wat daarmee gepaard gaan of oor die aanpassings wat gemaak sal moet word nie. Die hoofdoel van aftrede is om die persoon te vergoed vir sy bydrae en diens aan die gemeenskap - om op sy oudag te kan ontspan, behoort die hoogtepunt van sy prestasie te wees. Ons houding teenoor aftrede beslis egter die mate van toekomsgeluk. Nuwe uitdagings en geleenthede moet in die lewe gevind word om ons geestesen liggaamlike vermoëns te stimuleer. Voorbereiding vir bejaardheid en aftrede is dus gebiedend noodsaaklik om 'n bevredigende lewenspatroon by die indiwidu aan te kweek (1:p78).

Dit kan 'n gelukkige en interessante lewenstydperk wees indien die mens:

betyds gebruik maak van sy gesonde verstand deur

- bewustelik te leer om geld te spaar;

- te lewe binne 'n maandelikse begroting;

- oordeelkundig gebruik te maak van assuransiepolisse en verskillende hulpskemas;

- 'n goed opgestelde testament om voorsorg te tref vir gade;

sorg vir 'n gesonde liggaam deur

- gesonde eetgewoontes;

- gesonde oefening;

- drank en rookgewoontes in oënskou te neem;

sorg vir gelukkige en gesonde gees deur

- te waak teen 'n gesindheid van kritiek, foutvindery, afguns en liefdeloosheid - dit neem toe met ouderdom;

- 'n sin vir humor te kweek;

- belangstellings te kweek;

- 'n geloofsanker te hê.

Voorbereiding vir aftrede is ' $n$ lewenslange taak wat al vroeg in 'n mens se lewe behoort te begin om sodoende 'n blywende, gelukkige en bevredigende lewenspatroon te ontwikkel wat na aftrede voortgesit kan word (8:p1-18). Aftree moet gesien word as 'n veranderde leef- wyse - 'n nuwe fase in die mens se lewe waarin geluk en tevredenheid gevind kan word.

\section{SPESIFIEKE PROGRAMME}

Die behoefte aan programme vir voorbereiding vir aftrede is angewakker deur 'n konferensie wat in 1966 deur die Nasionale Ontwikkeling en Bestuurstigting van SuidAfrika in Kaapstad gereël is en deur oorsese deskundiges bygewoon is. 'n Gidskomitee is in die lewe geroep om ondersoek in te stel na maniere waarop Suid-Afrikaners gehelp kan word om hulle self te help in hierdie opsig. Hierdeur is die inisiatief aan die gemeenskap oorgelaat om in hul eie behoeftes te voorsien. Tot nou toe is daar geen program wat deur die Departement Gesondheid en Welsyn aangebied word nie, maar hierdie onderwerp is aangeraak in 1967 en weer in 1972 tydens konferensies oor bejaardesorg wat deur die destydse Departement Volkswelsyn en Pensioene gereël is.

\section{Die Aftredingsvereniging}

Die doelwit van hierdie Vereniging is om navorsing en onderrig aangaande die fisiologiese en sielkundige veranderinge wat met aftrede gepaard gaan, te onderneem.

Hierdie organisasie is in Mei 1967 in die lewe geroep en is as 'n geïnkorporeerde vereniging sonder winsbejag geregistreer. Die hoofkantoor is in Johannesburg en daar is oor ' $n$ tydperk takke gestig in Durban, Pretoria, Kimberley, Witbank, Wes-Transvaal, Noord-Natal en in die Laeveld. Die vereniging bestaan uit ongeveer 105 maatskappye en groepe wat die belange van hul werknemers op die hart dra. Die lidmaatskappye betaal ' $n$ jaarlikse ledegeld in ooreenstemming met die aantal Blanke werknemers bo die ouderdom van 45 jaar op hulle diensstaat. Indien die maatskappy hul Swart werkers wil betrek, moet ' $n$ addisionele bedrag betaal word. Die werkgewer vaardig sy werknemers af om die kursus by te woon. Die toename in bywoning van die kursusse het gestyg van 21 in 1968 tot 6,000 in 1979 . In Johannesburg word nege vier-dag kursusse per jaar aangebied en in Pretoria vier twee-dag kursusse.
Die gemiddelde ouderdom van persone wat die kursusse bywoon is 53 jaar. In sekere sentra word die kursus vir Blanke en Swart persone aangebied.

Die program wat aangebied word sluit 'n verskeidenheid van onderwerpe in. Finansies, waaronder assuransie, pensioen en testamente bespreek word, word gedek. Woning behels nie net die fisiese gebou nie, maar aandag word ook aan ' $n$ aangename omgewing sowel as gevare van verhuising gegee. Handvaardighede soos mosaiek, koper en kleimodellering word demonstreer. 'n Geneesheer lewer 'n praatjie oor fisiese en psigiese gesondheid. Persone wat belangstel in kuns - olieverf, waterverf en andere - kry basiese lesse. Diegene wat in verdere onderrig belangstel word uitgenooi na 'n skildervakansie van een week in die Malutiberge. Die koste word deur die persoon self gedra, maar twee kunslesse per dag word aangebied. In die program word ' $n$ beroep vir besoldiging ook bespreek. 'n Skyfiereeks word gewys oor verskillende reise wat onderneem kan word. Hierdie bespreking dek aspekte soos argeologie, geologie en Boesmankuns, sodat besef word dat daar op ' $n$ reis baie is om te leer en die persoon nie homself net aan gerief oorgee en 'n tuisblyreisiger word nie.

Tydens die program word daar klem gelê op volwassene onderrig. Die instelling wat aangekweek word, is dat jy nooit te oud is om te leer nie. Dit word nie van die afgetredene verwag om die skoolkurrikulum deur te werk nie, maar 'n houding van belangstelling moet altyd teenwoordig wees. Ook word die persone daaraan herinner dat korrespondensiekursusse in ons land geweldig uitgebrei het.

'n Oorsig van moderne skrywers word gegee en bekende letterkundige werke kom weer onder die aandag. Ook 'n musieksessie word aangebied waar verskillende instrumente aan die gehoor getoon word. Daar word veral aandag gegee aan die persoon wat as kind ' $n$ instrument bespeel en dit totaal verleer het. Die gedagte is daar dat hierdie persone weer hulle talente moet opknap en selfs weer 'n paar lesse neem. Ook saamsing word gehou 
van liedjies wat ongeveer 10 jaar gelede gewild was. Voorheen is die kwessie van geloof ook bespreek, maar weens die groot verskeidenheid gelowe, is dit gestaak. Wat wel dwarsdeur die kursus beklemtoon word is hoop, vertroue en liefde.

'n Werkverskaffingsburo is met die Vereniging geaffilieer, wat persone bo 60 jaar wat wel moet werk help. As persone net besig wil wees en nie die geld werklik nodig het nie, word vrywillige hulp aan organisasies, hospitale en so meer voorgestel. 'n Adviesburo gee inligting oor die kursusse. Die voortsettingsklub hou persone op hoogte van verwikkelinge deur middel van 'n kwartaalblad S.A. Maturity. Hulle reël ook uitstappies, staptoere en opera-aande teen 'n verminderde tarief. Die slagspreuk van die Vereniging is:

Dink aan die toekoms... dit is waar $u$ die res van u lewe sal deurbring.

\section{Yskorprogram}

Eerstens het die afgetrede werknemers van Yskor besef dat hulle nie voorberei was op hierdie lewensfase nie. Tweedens het die werknemers wat oorsee gegaan het in aanraking gekom met ander groot staalmaatskappye waar sulke kursusse aangebied is. Hierdie twee groepe het 'n leemte identifiseer en hul behoefte aan hul werkgewer gestel, met die gevolg dat 'n program ongeveer twee jaar gelede geloods is. Maatskaplike werkers wat spesifiek opgelei is in onderrig, bied kursusse by die groot Yskorsentrums aan. Die kleiner sentrums word deur die maatskaplike werkers van die hoofkantoor in Pretoria bedien. Tot dusver word die program slegs vir Blankes aangebied.

Die program duur een week voltyds en werkers word 20 jaar voor. 10 jaar voor en net voor aftrede betrek. Audio-visuele hulpmiddele word baie effektief gebruik en die nodige fasiliteite is beskikbaar. Die program word vergelyk met 'n wiel - die as en speke waarvan essensieel is vir die effektiewe funksionering van die wiel. Die grootte en effektiwiteit van die as is die deurslaggewende faktor. Psigiese voorbereiding en geestelike instelling word met hierdie as vergelyk.
Verdere aspekte wat behandel word, is om te waak teen 'n nuttelose, onaktiewe lewe. Die waarde van belangstelling in aktiwiteite of stokperdjies word beklemtoon meer as een sodat die persoon binnenshuise en buitenshuise belangstellings het.

Finansiële beplanning is ook hoog op die rangorde van prioriteite. Verbande op 'n huis word bespreek, die aspekte van ophoping en uitbetaling van verlof met aftrede word uitgewys en daar word ook aan die persoon verduidelik presies wat sy pensioenskema behels.

Dit is moeilik om te bepaal watter verdere aspek die belangrikste is. Persoonlike verhoudings, gesondheid, boedels en testamente en verblyf met aftrede word bespreek. Persone word aangemoedig om al hierdie aspekte met hul wederhelf te bespreek sodat daar saam besin kan word.

Die doelstellings van die program is dus:

- om die persone bewus te maak van die belang om te beplan vir 'n bevredigende aftrede;

- om die negatiewe houding en vrees waarmee persone aftrede benader te verminder;

- om praktiese en nuttige inligting te verskaf oor toepaslike aspekte;

- om persone 'n geleentheid te bied om hul vrese te deel en van ander te leer;

- om persone bewus te maak van beskikbare fasiliteite vir hulp aangaande hulle aftrede;

- om nie oplossings te verskaf nie, maar om persone bewus te maak van alternatiewe keuses met betrekking tot aftrede.

\section{Nasionale Raad vir Bejaardes}

Hierdie Raad is ' $n$ welsynsorganisasie wat met die Westelike Provinsiale Raad vir Aftrede van Kaapstad geaffilieer is. 'n Hele aantal jare gelede het die Nasionale Raad met 'n voorbereidingsprogram vir aftrede begin. Die Raad word deur maatskappye genader om die program vir hul werknemers aan te bied. Die maatskappy onderneem dan om die verblyf- en reiskoste van die spreker te dra. Na die afloop van die kursus skenk die be- trokke maatskappy meestal 'n donasie aan die Raad.

'n Boekie wat deur hulle uitgegee word, dek die program oorsigtelik. Daar word beklemtoon dat bywoning van die kursus van onskatbare waarde vir die indiwidu sal wees. Die volgende sake word kortliks bespreek, wenke word gegee en daar is ook heelwat stof tot nadenke:

- aanpassing na aftrede;

- pensioen en beleggings;

- 'n begroting laat klop;

- herindiensneming;

- gesondheid;

- reëlings vir verblyf;

- familie en vriende;

- bedrywighede, belangstellings en tydverdrywe;

- boedels, testamente en trusts.

Die Raad poog nie om aan die gemeenskap voor te skryf wat hulle moet en nie moet doen nie. Die doel is slegs om die indiwidu se belangstelling te prikkel sodat hy aan sy aftrede sal dink en dan tot daadwerklike beplanning daarvoor oorgaan.

\section{A.T.K.V.}

'n Tak van hierdie Vereniging is die verantwoordelikheid opgelê om 'n program vir die voorbereiding vir aftrede van die spoorwegwerknemer aan te bied. Een van die probleme wat geïdentifiseer is, is dié van hooggeplaastes in diens van Spoorweë wat gewoond was aan belangrike persoon-behandeling. Met aftrede is hierdie besondere behandeling die persoon ontneem en het dit verwarring en wanaanpassing veroorsaak.

Daar is verlede jaar met die aanbieding van die program begin vier kursusse per jaar, een in elke provinsie - en daar word beoog om dit tot twee kursusse per jaar per provinsie uit te brei, 'n Keuse word aan werknemers van die Spoorweë gestel om lid van die A.T.K.V.-voorbereidingsprojek te word. Ledegeld (wat dus nie-verpligtend is) beloop $\mathrm{R} 2,00$ per maand per gesin of R1,50 per maand vir 'n enkeling.

Die program word deur die A.T.K.V.-tak gereël, maar die persone wat die lesings aanbied is deskundiges op hul gebied byvoorbeeld gesondheid deur 'n geneesheer, boedels en testamente deur 'n 
wetsgeleerde, familie se betrokkenheid deur 'n sielkundige. Die program behels ook aanpassing na aftrede, die pensioenskema en finansiële beplanning. Laasgenoemde word as baie belangrik beskou aangesien die spoorwegpensioenskema een van die beste in die land is. ' $n$ Groot bedrag geld word aan 'n persoon wat lang diens het uitbetaal, en met finansiële beplanning word leiding aan hom gebied ten opsigte van die oordeelkundige gebruik en belegging van dié bedrag. Groepbesprekings word ook gehou.

Biokinetika-lesings word gegee om fiksheid te bevorder. Dit word beklemtoon dat 'n persoon nie noodwendig $5 \mathrm{~km}$ per dag hoef te draf om fiks te wees nie en daar word dus ook alternatiewe voorstelle aan die hand gedoen en leiding gegee. Die biokinetikus wat die lesings aanbied, is aan die gesondheidsentrum van die Warmbad Vakansie-oord verbonde.

\section{DIE ROL VAN DIE VER- PLEEGKUNDIGE}

Die verpleegkundige is inherent toekomsgerig in haar omgang met die mens. In die voorgeboorte-situasie, moeder-en kinderdienste en skoolgeneeskundige dienste, is sy inderdaad betrokke by die verwerkliking van 'n gesonde lewensfilosofie by die gemeenskap. Sy is instrumenteel in die verantwoordelikheidsin wat by die indiwidu en sy gesin ten opsigte van sy eie gesondheid moet posvat.

Tydens die volwassewordingsproses leer die verpleegkundige om rigtinggewend op te tree. Sy word geleer om behoeftes te identifiseer en daadwerklik op te tree. Voorbereiding vir aftrede is ' $n$ aktuele saak - dit moet egter soos 'n veldtog teen rook non-direktief benader word. Die moete en moenies behoort nie uitgespel te word nie. Die verpleegkundige moet die teikengroep op 'n subtiele wyse beïnvloed sodat die gemeenskap self die behoefte identifiseer en dan self daartoe oorgaan om hierdie behoefte te bevredig of op te los. Na my mening is bogenoemde die basis waarop die res dan uitgebou kan word.

Daarna moet inligting aangebied word. In die akademiese hospitale kan programme vir personeel aan- gebied word. Mediese studente en studentverpleegkundiges moet hierby betrek word sodat hulle bewus kan wees van die belang van voorbereiding vir aftrede. Die algemene praktisyn sal dan oor basiese kennis beskik sodat hy die belangrikheid van voorbereiding vir aftrede aan die indiwidu en die gesin kan oordra. Indien hierdie persone dan 'n leemte by hulself voel, sal hulle ' $n$ poging aanwend om 'n uitgebreide program by te woon.

In die algemene hospitaal is daar areas waar die verpleegkundige die boodskap op 'n subtiele wyse kan oordra soos in die buitepasiëntekliniek en die koronêre eenheid, om maar net twee te noem. Tydens voorligting oor 'n gesonder lewenswyse kan net die gedagte van voorbereiding vir aftrede genoem word.

Die gemeenskapsgesondheidsverpleegkundige het natuurlik 'n reuse taak. Eerstens moet sy 'n model wees. Sy moet self in die gemeenskap deelneem aan buitemuurse bedrywighede en die ideaal van 'n voorbereide aftrede voorleef. In haar daaglikse taak propageer sy tog 'n gesonde lewensfilosofie, maar sy moet ook in die gemeenskap die gedagte van voorbereiding vir aftrede laat posvat. Indien sy hierin slaag, sal die gemeenskap wat sy bedien self die leemte identifiseer en haar dan moontlik nader om groepe toe te spreek, soos vroueverenigings en oueraande by skole.

Die skoolverpleegkundige bevind haar ook in 'n netelige situasie. Dit gaan nie help om vir kinders in die skool toe te spreek en vir hulle te sê: Eer jou vader en jou moeder sodat jou dae verleng mag word nie. Sy moet haar onverpoos daarvoor beywer om 'n gesonde lewenswyse by die kind in te skerp. Weer eens op 'n subtiele wyse, moet sy die kinders se houding oor bejaardheid positief beïnvloed. Die jongmens moet insien dat bejaardheid slegs ' $n$ lewensfase is waarin die persoon homself uitleef en bekroon word vir dit wat hy bereik het. Sy moet ' $n$ houding van respek vir die bejaarde by die jongmens kweek.

Die gemeenskap moet ook in hierdie verband heropgevoed word sodat die samelewing nie soveel klem lê op die jongmens, sy vermoëns en prestasies nie. Die be- jaarde moet die geleentheid gegun word om sy plek in die samelewing met waardigheid vol te staan. Dit klink miskien idealisties, maar doen ons nie 'n stap in die regte rigting deur die beoogde Jaar van die Bejaarde in 1982 nie? Kan ons nie tydens die beoogde projek probeer om die jongmens in sy eie gemeenskap by die bejaarde te betrek nie? As die kind by ' $n$ bejaarde se huis 'n takie verrig, sal die kind self kan sien dat die bejaarde 'n gelukkige bestaan in die gemeenskap voer. Sal dit dan nie sy houding oor bejaardheid positief beïnvloed nie?

Die persoon wat reeds afgetree het kan ook bewus gemaak word van die feit dat hy wel nog die potensiaal het om sy gemeenskap te dien. Sekerlik is daar talle afgetredenes wat oor die vermoë en vaardigheid beskik om klein takies vir iemand in 'n huis te kan verrig. Die gemeenskapsverpleegkundige kan hierdie potensiaal in 'n bejaarde identifiseer en weer net ' $n$ gedagte laat posvat.

Die bedryfsgesondheidsverpleegkundige kan ook 'n baie groot rol vervul. Sy kan optree deur die gedagte van voorbereiding vir aftrede by die bestuur tuis te bring. ' $n$ Werknemer wat voorbereid en gelukkig aftree, sal op die lange duur vir die organisasie baie voordeel inhou.

En wat van ons eie organisasie? By takke van die Verpleegstersvereniging word daar jaarliks geld ingesamel vir die Suid-Afrikaanse Verpleegsterstrustfonds. Behoort ons nie ook aandag te gee aan voorbereiding vir aftrede nie? Die Verpleegstersvereniging vervul wel indirek 'n rol deur assuransiemaatskappye vir verpleegkundiges goed te keur, maar kan hulle nie ook 'n inligtingspamflet in hiedie verband aan die beroep verskaf nie? Is die Jaar van die Bejaarde nie ook 'n geleentheid om 'n program oor voorbereiding vir aftrede by takvergaderings aan te bied nie? Sodoende sal 'n groot aantal verpleegkundiges bewus word van die belang van voorbereiding vir aftrede en sal hulle dan daarin kan slaag om diegene met wie hulle in aanraking kom op non-direktiewe wyse positief te beïnvloed. 


\section{SLOTOPMERKING}

Aftrede moet dus positief benader word sodat hierdie lewensfase vir die indiwidu gelukkig en skeppend sal wees. Die indiwidu moet homself verstandelik en liggaamlik fiks hou en kontak behou met vriende wat 'n belangrike rol in sy lewe vervul het. Die mate van geluk wat die indiwidu na aftrede beleef sal slegs van homself afhang. 'n Mens se leefwyse, mentaliteit, karakter, sienswyse en lewensfilosofie dra alles by tot sy gelukkige en tevrede aftrede. (9:p8)

Mev. Z. Droskie het tydens die konferensie oor geriatriese sorg te
Pretoria in 1979 beklemtoon dat Die opvoeding van die gemeenskap om 'n gesonder, gelukkige oudag tegemoet te gaan, is van uiterse belang en meer aandag sal hieraan sowel as die uitbreiding van dienste, gegee moet word.

\section{BRONNELYS}

1. DROSKIE, Z. Maatskaplike werk met bejaardes met besondere verwysing na aanwending van maatskaplike hulpdienste. Nasionale konferensie oor bejaardesorg. Dept. Volkswelsyn en Pensioene. Pretoria 1979

2. FIELD. M. Aging with honour and dignity. C.C. Thomas Publishers. Illinois 1968.

3. HART. G.R. Retirement-a new outlook for the individual. Hartcourt Brace \& Co. New York. 1967.

4. LEVY, S M. The adjustment of the older woman: ef- fects of chronic ill health and attitudes toward returement. International journal of aging and human de velopment. Volume 12 No. 2 . 1980.

5. MCKENZIE, W. What every single girl should know. Choice Magazine. January, 1981

6. MOSSMAN, K., Looking forward to retirment. Ward Loch London. 1971

MULLER. O.H.. Preparing for the last fling. Curasio nis. Volume 4 No 1 1981.

8. RAATH, J.M., Voorbereiding vir die oudag. Konferensie insake bejaardesorg. Dept. Volkswelsyn en Pensioene, Pretoria 1967

\section{PUblikasies}

9. Aftrede die Goue jare. - Westelike Provinsie Raad vir Aftrede.

10. Die Aftredingsvereniging

ONDERHOLIDE (Persoonlik en/of telefonies)

A.T.K.V. - Johannesburg. Mnr. Van Wyk.

Bejaardesorg - Johannesburg. Mej. H.M Naude

Nasionale Raad vir Bejaardes. - Johannesburg. Mev. Nel. Retirement Association - Johannesburg. Mev S.E. Brooker.

Yskor Hoofkantoor Petoria. Mcv. K. Potgieter en Mnr. P. Venter.

Dept. Gesondheid en Welsyn - Precoria. Mej. $\mathrm{OH}$. Muller

\section{'N ONDERSOEK NA PARAMETERS VAN PROGNOSTIESE BELANG BY DIE HOOFBESEERDE PASIËNT - 'N VERPLEEGKUNDIGE STUDIE}

\section{Margaritha Johanna Hugo}

\author{
Departement Verpleegkunde, Universiteit van Pre- \\ toria \\ Magister Curationis (Gevorderde Algemene Ver- \\ pleegkunde)
}

\section{SAMEVATTING}

Die geweldige toename in ongelukke met gepaardgaande toename in ernstige hoofbeserings het daartoe aanleiding gegee dat navorsing op ' $n$ wye front gedoen word op soek na parameters van prognostiese belang by die hoofbeseerde pasiënt. Parameters van moontlike prognostiese belang, asook die patologie en meganismes van hoofbeserings word kortliks bespreek.

Die waarnemings wat deur die verpleegkundige gedoen word is ondersoek. Die essensie van noukeurige waarnemings word beklemtoon. Die navorser poog ook om verpleegkundiges positief te motiveer ten opsigte van die hantering en behandeling van die hoofbeseerde pasiënt met spesiale verwysing na die menswaardigheid van die bewustelose pasiënt.

Deur noukeurige waarnemings en goeie kommunikasie met die geneesheer, mag die verpleegkundige daartoe bydra dat die pasiënt se prognose sal verbeter en die mate van gestremdheid tot die minimum beperk word. Die navorser beveel aan dat 'n nabasiese kursus in neurochirurgiese verpleegkunde ingestel word. Dit kan daadwerklik bydra tot die suksesvolle behandeling van die hoofbeseerde pasiënt.

\section{DIE VERPLEEGKUNDIGE AS VERTOLKER VAN PASIËNTBEHOEFTES AAN DIE HOSPITAALBEPLANNINGSPAN}

\author{
Susanna Josina Fourie
}

\author{
Departement Verpleegkunde, Universiteit van Pre- \\ toria
}

Magister Curationis (Verplegingsadministrasie)

\section{SAMEVATTING}

Weens die vinnige tempo van ontwikkeling op mediese gebied en die verwagtinge wat 'n gemeenskap van 'n hospitaal koester, word daar vele eise aan die hospitaalbeplanningspan gestel.

Onder die talryke faktore van uiteenlopende aard wat die oorweging van die beplanners verdien, is pasiëntbehoeftes sonder twyfel dié oorweging na aanleiding waarvan alle besluite ten opsigte van beplanning geneem behoort te word.

In hierdie studie word daar gepoog om, aan die hand van 'n literatuurstudie, die mening van deskundiges en die ervaring van die navorser, te toon dat die verpleegkundige dié lid van die gesondheidspan is wat die volledigste vertolking kan gee van die pasiënt se behoeftes in die tydperk wat hospitalisering voorafgaan, asook tydens hospitaalverblyf.

In teenstelling met die ander lede van die gesondheidspan, het die verpleegkundige, uit die aard van haar deurlopende kontak met die pasiënt, die geleentheid om hom as totaliteit waar te neem. Sy kan sodoende pasiëntbehoeftes identifiseer en aan die beplanningspan vertolk met die oog op die voorsiening van die fasiliteite wat hierdie behoeftes ten beste bevredig. 